\title{
Identification of functional butanol-tolerant genes from Escherichia coli mutants derived from error-prone PCR-based whole-genome shuffling
}

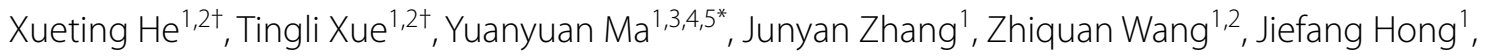
Lanfeng Hui ${ }^{6}$, Jianjun Qiao ${ }^{4,5}$, Hao Song ${ }^{4,5}$ and Minhua Zhang ${ }^{1,3}$

\begin{abstract}
Background: Butanol is an important biofuel and chemical. The development of butanol-tolerant strains and the identification of functional butanol-tolerant genes is essential for high-yield bio-butanol production due to the toxicity of butanol.

Results: Escherichia coli BW25113 was subjected for the first time to error-prone PCR-based whole-genome shuffling. The resulting mutants BW1847 and BW1857 were found to tolerate $2 \%(\mathrm{v} / \mathrm{V})$ butanol and short-chain alcohols, including ethanol, isobutanol, and 1-pentanol. The mutants exhibited good stability under butanol stress, indicating that they are potential host strains for the construction of butanol pathways. BW1847 had better butanol tolerance than BW1857 under 0-0.75\% (v/v) butanol stress, but showed a lower tolerance than BW1857 under 1.25-2\% (v/v) butanol stress. Genome resequencing and PCR confirmation revealed that BW1847 and BW1857 had nine and seven single nucleotide polymorphisms, respectively, and a common 14-kb deletion. Functional complementation experiments of the SNPs and deleted genes demonstrated that the mutations of $a \mathrm{crB}$ and rob gene and the deletion of TasA increased the tolerance of the two mutants to butanol. Genome-wide site-specific mutated strains DT385 (acrB $\mathrm{C}_{1198} \mathrm{~T}$ ) and DT900 (rob AT $686-7$ ) also showed significant tolerance to butanol and had higher butanol efflux ability than the control, further demonstrating that their mutations yield an inactive protein that enhances butanol resistance characteristics.
\end{abstract}

Conclusions: Stable E. coli mutants with enhanced short alcohols and high concentrations of butanol tolerance were obtained through a rapid and effective method. The key genes of butanol tolerance in the two mutants were identified by comparative functional genomic analysis.

Keywords: Escherichia coli, Butanol-tolerant mutants, Comparative functional genome, Rob, AcrB, Transcription regulator factor, Efflux pump, Quorum-sensing signal transporter

\section{Background}

Butanol is a potential superior alternative to ethanol as biofuel, with a higher energy density, lower hygroscopicity

\footnotetext{
*Correspondence: myy@tju.edu.cn

${ }^{\dagger}$ Xueting He and Tingli Xue share co-first authorship and have equal contribution to the study

${ }^{1}$ Biomass Conversion Laboratory, R\&D Center for Petrochemical Technology, Tianjin University, Tianjin 300072, People's Republic of China Full list of author information is available at the end of the article
}

and volatility, and less corrosive. Butanol has also been used in a wide range of fields, including the food, plastics, and pharmaceutical industries [1]. Engineering a butanol biosynthetic pathway into Escherichia coli (E. coli) could produce $n$-butanol at the level of grams per liter and compete with the traditional industrial producer, genus Clostridium [1-3]. However, the poor butanol tolerance of bacteria leads to the inhibition of cell growth and a decrease in butanol yield, which has been a bottleneck in 
biobutanol production. Thus, the economic production of butanol relies on the improvement in butanol tolerance of the bacterial producers $[4,5]$.

To improve the robustness of chassis strains, rational metabolic engineering strategies have been used to generate butanol or other fuel-tolerant mutants of $E$. coli $[4,6]$. Genes in relation to membrane function and ion transport system have been reported to respond to butanol stress, the tolerance to which could be improved by the overexpression of genes encoding the efflux pump [7-9], ion transport proteins entC and feoA $[10,11]$, and membrane-targeted metallothionein [12]. Heat shock protein (HSP) genes also respond to butanol stress; as such, their upregulation or overexpression could also lead to an increase in tolerance [13].

The mechanism of butanol tolerance, thus, involves multiple physiological processes mediated by a gene network. Butanol-tolerant E. coli strains are also obtained using random engineering strategies, such as global transcription machinery engineering (GTME) and evolution engineering, among others [14-17]. These mutants developed by random mutation and selection generally show a greater tolerance than those with functional changes in one gene, and could tolerate $1-2.0 \%(\mathrm{v} / \mathrm{v})$ butanol $[16,18]$. This may due to the fact that multiple mutated genes endow strains with a greater tolerance. When membrane-related functional genes are overexpressed in butanol-tolerant E. coli through evolution, the final engineered strain can grow under $2 \%$ butanol stress [18], indicating that a combinational strategy could effectively improve tolerance. If the key butanol-tolerant genes could be identified and clarified, these favorable mutations could be introduced to chassis strain, also referred to as inverse metabolic engineering [19]. Nevertheless, the genes of many mutants have not yet been functionally identified, which limits our understanding of the butanol tolerance mechanism as well as the potential to obtain butanol-tolerant characteristics.

It is still challenging to develop high butanol-tolerant strains using metabolic engineering or combinatorial approach because of the current limited understanding of the tolerance mechanisms; it is first necessary to establish a simple and rapid evolution strategy for the acquisition of resistant mutants, to thereafter identify the functional stress-tolerant genes and elucidate the mechanism of butanol tolerance. In this study, error-prone PCR (epPCR)-based whole-genome shuffling was used to improve the butanol tolerance of E. coli BW25113. As a result, two mutants tolerating $2 \%(\mathrm{v} / \mathrm{v})$ butanol were successfully obtained. The mutation sites of the two strains were then identified by whole-genome resequencing, and comparative functional genomic analysis was performed to identify the key butanol-tolerant genes.

\section{Results}

Isolation and characterization of butanol-tolerant mutants by error-prone PCR-based whole-genome shuffling

Error-prone PCR-based (epPCR) genome shuffling was used to screen butanol-tolerant strains. Using this method, epPCR products were integrated into the genome of host cells by electro-transformation (Fig. 1), $[20,21]$. As such, BW25113 (pKD46) was used as an initial strain to improve recombinant efficiency via lambdaRed recombinase genes in a pKD46 plasmid. Strains exhibiting a butanol-tolerant phenotype were obtained by the first round of shuffling, where BW184 presented the best tolerance. The cell density of BW184 increased eightfold from the initial levels under 1.0\% (v/v) (always expressed as $\mathrm{v} / \mathrm{v}$ ) butanol stress at $12 \mathrm{~h}$, whereas the growth of BW25113 was completely inhibited. BW184 was, thus, used as a starting strain for next round of genome shuffling, and the pKD46 plasmid was transferred to BW184 for high-efficient recombination of PCR products to genome. The mutant strains BW1847 and BW1857 were obtained from the second round of shuffling, reaching a maximum $\mathrm{OD}_{600}$ of 0.69 and 0.50 , respectively, which was 5.0- and 3.6-fold higher than that of BW25113, respectively. BW1847 was delayed $12 \mathrm{~h}$ to enter a stable phase (Fig. 1). The two strains, thus, showed more tolerance than both the initial strain and BW184, and their tolerance properties were further investigated.

\section{Tolerance of BW1847 and BW1857 to various short-chain alcohols}

BW1847 and BW1857 had a higher tolerance to 0.75$1.5 \%(\mathrm{v} / \mathrm{v})$ isobutanol, $0.1-0.6 \%$ 1-pentanol, and $4.5-$ $7 \%$ ethanol (Fig. 2) compared to the control. BW1847 showed greater tolerance to isobutanol than BW1857 in a relatively low concentration $(0.75-1.25 \%)$ of isobutanol stress. Nevertheless, it had a relative low cell density compared to BW1857 under 1.5\% isobutanol and 7\% ethanol stress, which also demonstrated that BW1857 had a better tolerance to high concentrations of isobutanol and ethanol. Interestingly, this trend was similar to that observed in subsequent butanol stress experiments. BW1847also had higher relative cell densities than BW1857 in the presence of 0.1-0.4\% 1-pentanol, indicating that BW1847 had a greater tolerance to 1-pentanol. These results indicate that the mutant strains exhibited resistance to short-chain alcohols with different tolerance characteristics.

\section{Growth and stability under varying butanol stress}

BW1847 and BW1857 strains were serially subcultured to 50 generations in LB media without butanol for stability evaluation of butanol tolerance. Both subcultured and non-subcultured strains of 50 generations were 



Fig. 1 Screening of butanol-tolerant E. coli strains by epPCR-based genome shuffling. a Schematic of epPCR genome shuffling. b Growth of transformants under $0.95 \%(\mathrm{v} / \mathrm{V})$ butanol stress
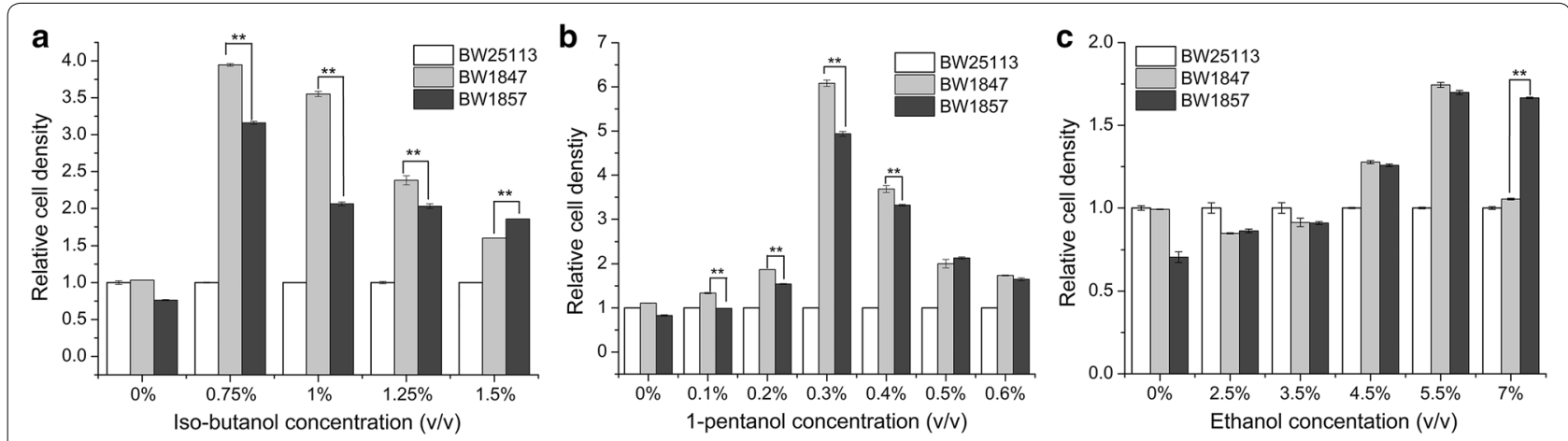

Fig. 2 Relative cell densities of strains in the presence of various concentrations of short-chain alcohols. Strains were cultured under different concentrations of iso-butanol (a), ethanol (b) and 1-pentanol (c), and their $\mathrm{OD}_{600}$ was determined. The relative cell density is expressed as a ratio of the biomass value of mutants to that of parallel culture BW25113 under the same culture conditions

synchronously cultured for growth detection. Strains subjected to 50 generations of subculture had similar growth curve profiles to those not subjected to subculture in the presence of $0-1.5 \%$ butanol, indicating that BW1847 and BW1857had good butanol-tolerance stability (Fig. 3a-e), making them promising candidates for further industrial application.

BW1857 showed slower growth and lower cell density than BW25113 and BW1847 both under 0.75\% butanol stress conditions and without butanol, demonstrating that growth of BW1857 was inhibited (Fig. 3a, b). However, BW1857 had a higher cell density than BW1847 in the presence of $1-1.5 \%$ butanol, indicating that BW 1857 exhibited a better tolerance in high butanol concentrations (Fig. 3c-e). The cell densities of BW1847 and BW1857 were $68 \%$ and $204 \%$ higher, respectively, than that of the control BW25113 at $1.5 \%$ butanol, demonstrating their tolerance to high concentrations of butanol (Fig. 3e). BW1857 showed an inhibited and enhanced growth under low and high concentrations of butanol, respectively, implying that it contains multiple gene mutations, some of which may lead to improved butanol tolerance, with others resulting in growth inhibition.

Growth under high concentrations of butanol was evaluated (Fig. 3f). BW1847 and BW1857 showed 1.5and 2.7-fold, and 3.5- and 5.9-fold increased growth compared to the wild-type in the presence of 1.6 and $1.8 \%$ butanol, respectively. The cell growth of BW1847 and BW1857 was $1.9-3.7 \%$ and $16.5-17.3 \%$, respectively, of the control strain under high butanol stress (1.9$2.0 \%$ ). These data demonstrate that the butanol tolerance of the two mutants was significantly higher than that of BW25113, and they could tolerate 2\% butanol. BW1857 showed a relatively higher tolerance than BW1847 in concentrations of butanol above 1.25\% (Fig. 3c-f).

\section{Genome-wide identification of mutations by comparative genomics}

The mutations in the genomes of BW1847 and BW1857 were identified by resequencing using the genome 
a

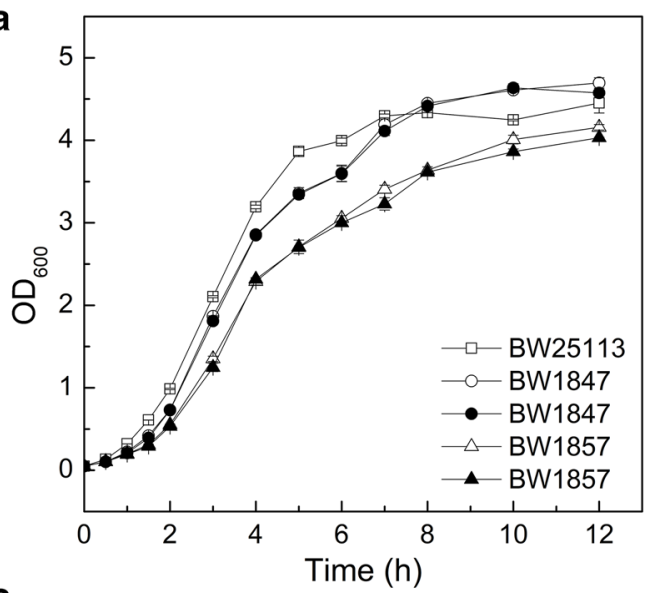

C

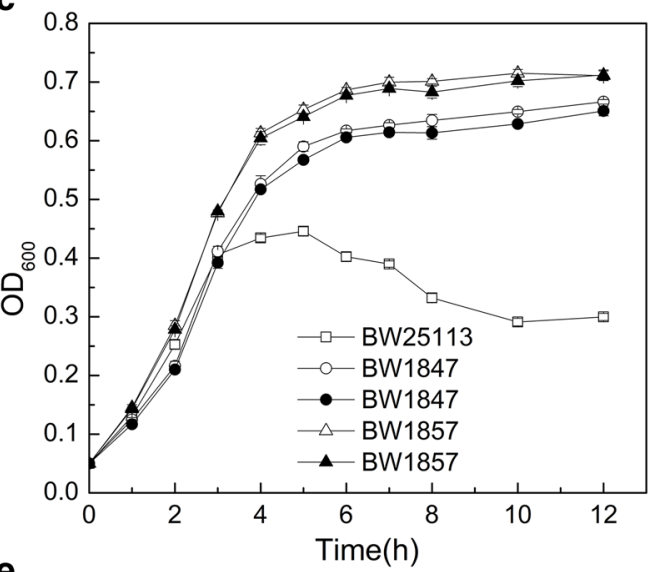

$\mathbf{e}$

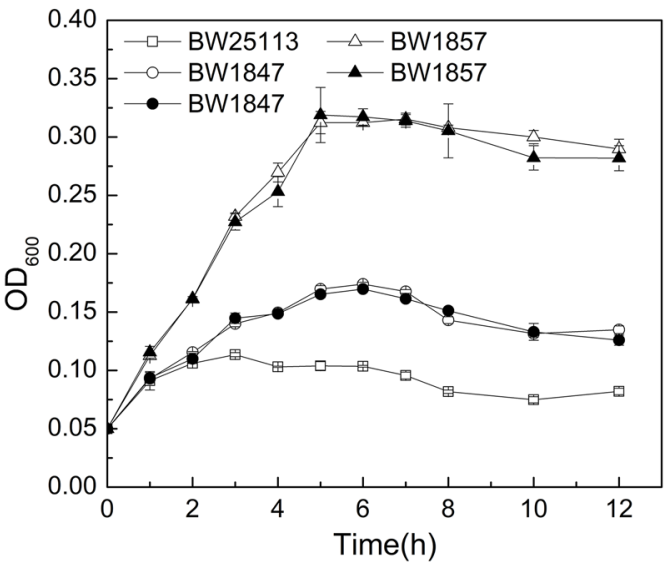

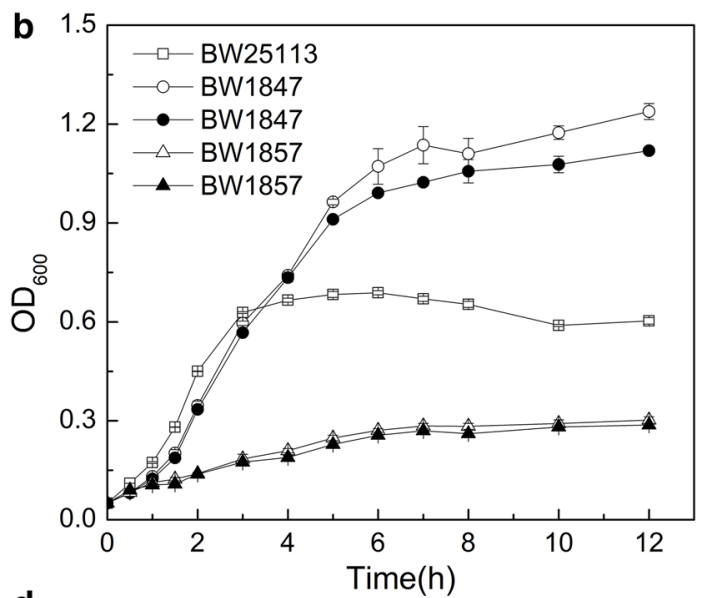

d
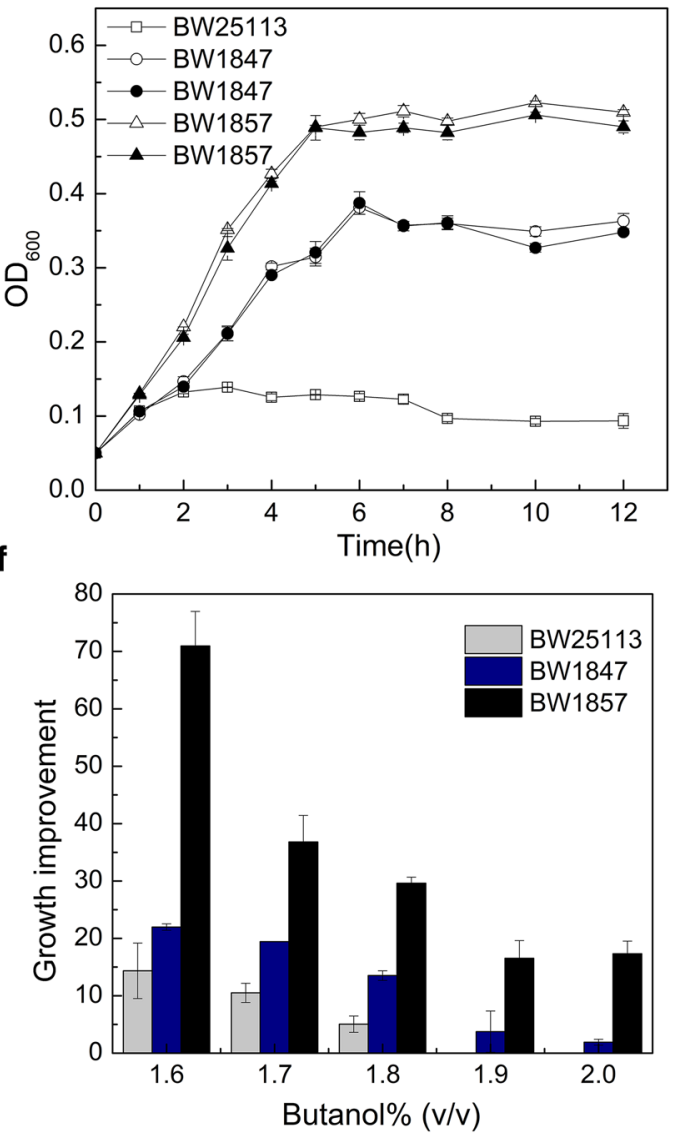

Fig. 3 Evaluation of butanol tolerance stability and high-concentration butanol tolerance of BW1847 and BW1857. Strains were cultured in LB containing 0 (a), 0.75 (b), 1.0 (c), 1.25 (d), or 1.5\% (e) (v/v) butanol. Solid and hollow symbols indicate the strains subjected or not, to 50 generations of subculture, respectively. Rectangles, circles, and triangles represent the initial strains BW25113, BW1847, and BW1857, respectively. f Growth of strains cultured in $1.6-2.0 \%$ butanol

sequence of the starting strain, BW25113 (NZ CP009273.1), as a reference control. PCR amplifications of the mutated (Table 1) and deleted genes were then performed to confirm the changes in the two mutants (Additional file 1: Additional data). Both BW1847 and
BW1857 had a deletion fragment of $14 \mathrm{~kb}$ containing seventeen genes (Additional file 1: Additional data, Figure S1; Table S1). BW1847 and BW1857 had a total of nine and seven mutations, respectively. They had five common single nucleotide polymorphisms (SNPs) (Table 1), 
and an extra four and two mutations in BW1847 and BW1857, respectively. Of the 11 mutations, seven were missense mutations and four were nonsense mutations (Table 1).

\section{Functional identification of mutated genes in BW1847 and BW1857}

Functional complementation experiments of each mutated gene (Tables 1,2) were performed to examine their involvement in $n$-butanol tolerance (Additional file 1: Tables S1-S6, Additional data). When the functional complementary strains of the $a c r B$ gene (RS02385) were cultured in media without butanol, they all showed similar growth trends, indicating that the deletion and overexpression of $a c r B$ gene did not affect growth (Fig. 4a). The maximum cell density of the mutated $a c r B$ $(1198 \mathrm{C}>\mathrm{T})$ overexpression strains, BW25113 (pM385) and D385 (pM385), was 1.9- to 2.1-fold higher than the corresponding control strains, BW25113 (pBAD30) and D385 (pBAD30), under 0.7\% butanol stress. Nevertheless, the growth of $a c r B$ overexpression strains, BW25113 (pW385) and D385 (pW385), decreased 13.5-18.9\% compared to that of the controls, BW25113 (pBAD30) and D385 (pBAD30)(Fig. 4b), indicating that the mutation $(1198 \mathrm{C}>\mathrm{T})$ of $a c r B$ causes an increase in the butanol tolerance of BW1847. The cell density of BW25113 (pM385) was significantly increased compared to that of BW25113
(pBAD30), indicating that the $1198 \mathrm{C}>\mathrm{T}$ mutation must be dominant since it significantly improves the tolerance even when wild-type acrB is present.

The deletion and overexpression of the rob gene (RS22900) also had no influence on growth (Fig. 4c). The rob deletion mutant D900 (pBAD30) showed 1.6-fold higher maximum cell density than BW25113 (pBAD30). Nevertheless, the overexpression of the rob gene resulted in a $37.5-57.0 \%$ decrease of growth under $0.7 \%$ butanol stress, indicating that the deficiency of rob led to an enhanced butanol tolerance. The complementation strain D900 (pM900) showed an inhibited growth similar to that of D900 (pBAD30) under butanol stress (Fig. 4d), indicating that the overexpression of the truncated $r o b$ gene was unable to restore the function of rob. This also demonstrates that the deletion of the $\mathrm{AT}_{686-7}$ base in the rob gene in BW1847 causes an inactivation of Rob function, which improves the butanol tolerance of BW1847. Another 9 mutated genes, including $y h c D$ (RS14165) and nusG (RS20660), were identified but had no distinct influence on growth or butanol tolerance.

\section{Functional identification of deleted genes}

The deleted 14-kb fragment contained 17 genes, in which the pntA (RS08390) and pntB (RS08385) belonged to one operon and encoded the alpha and beta subunits

Table 1 Mutations identified in the BW1847 and BW1857 strains

\begin{tabular}{|c|c|c|c|c|c|c|}
\hline Strains & Gene/LC & Function & Mutation $^{a}$ & Gene position/length & Genome position & Effect $^{b}$ \\
\hline \multirow{6}{*}{$\begin{array}{l}\text { BW1847 } \\
\text { and } \\
\text { BW1857 }\end{array}$} & cdsA/RS00875 & Phosphatidate cytidylyltransferase & $\mathrm{G} / \mathrm{T}$ & $751 / 858$ & 192,914 & $G(251) C$ \\
\hline & pgsA/RS10005 & $\begin{array}{l}\text { CDP-diacylglycerol-glycerol-3-phos- } \\
\text { phate 3-phosphatidyltransferase }\end{array}$ & $\mathrm{T} / \mathrm{G}$ & $446 / 594$ & $1,985,853$ & $V(149) G$ \\
\hline & yheQ/RS11070 & Hypothetical protein & $\mathrm{T} / \mathrm{G}$ & $1843 / 1845$ & $2,204,421$ & $E(615)^{c}$ \\
\hline & hycD/RS14165 & Formate hydrogenlyase subunit & $C / A$ & $899 / 1572$ & $2,839,873$ & $A(300) E$ \\
\hline & as/B/RS19735 & Anaerobic sulfatase maturase AsIB & $\mathrm{T} / \mathrm{A}$ & $1223 / 1538$ & $3,977,540$ & $V(408) E$ \\
\hline & RS08320-RS08395 & & & & $1,658,639-1,672,922$ & 14-kb deletion \\
\hline \multirow[t]{4}{*}{ BW1847 } & acrB/RS02385 & $\begin{array}{l}\text { Multidrug efflux RND transporter per- } \\
\text { mease subunit AcrB }\end{array}$ & $\mathrm{C} / \mathrm{T}$ & $1198 / 3792$ & 478,662 & $L(400) F$ \\
\hline & spoT/RS18950 & $\begin{array}{l}\text { Bifunctional (p)ppGpp synthetase II/ } \\
\text { guanosine-3',5'-bis pyrophosphate } \\
\text { 3'-pyrophosphohydrolase }\end{array}$ & $\mathrm{G} / \mathrm{T}$ & $1882 / 2109$ & $3,817,641$ & $E(628)^{c}$ \\
\hline & nusG/RS20660 & $\begin{array}{l}\text { nusG transcription termination/antiter- } \\
\text { mination }\end{array}$ & $\mathrm{G} / \mathrm{T}$ & $436 / 546$ & $4,168,106$ & G (146) C \\
\hline & $\mathrm{rob} / \mathrm{RS} 22900$ & $\begin{array}{l}\text { Right oriC-binding transcriptional } \\
\text { activator, AraC family }\end{array}$ & AT/ & 1379 & $4,624,441(2)$ & Deletion $^{c}$ \\
\hline \multirow[t]{2}{*}{ BW1857 } & rp/B/RS17195 & $50 S$ ribosomal protein L2 & $\mathrm{T} / \mathrm{A}$ & $491 / 822$ & $3,444,233$ & I (164) N \\
\hline & infB/RS16425 & Translation initiation factor IF-2 & & $331-555 / 2673$ & $3,308,845-3,309,069$ & 225 bp deletion ${ }^{c}$ \\
\hline
\end{tabular}

LC locus number

a The nucleotide on the left of the backslash was deleted in the corresponding gene, and that on the right of the backslash was inserted in the corresponding gene

b Amino acid position is in parentheses, amino acid residue on the left and right side of parentheses denotes the original and that substituted in the corresponding protein, respectively

c Termination codon 
Table 2 Strains used in functional complementary study

\begin{tabular}{|c|c|c|}
\hline Strains & Description & Sources \\
\hline E. coliTop10F' & Host for plasmid construction & Lab stock \\
\hline E. coli BW25113 & 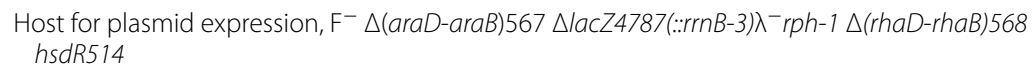 & Lab stock \\
\hline BW25113 (pBAD30) & pBAD30 is a arabinose-inducible expression vector, with ori 15A replicon, $\mathrm{Ap}^{R}$ & This study \\
\hline BW25113 (pW/M005) & BW25113 (pBAD30 carries wild/mutated pgsA) & This study \\
\hline BW25113 (pW/M070) & BW25113 (pBAD30 carries wild/mutated yehQ) & This study \\
\hline BW25113 (pW/M165) & BW25113 (pBAD30 carries wild/mutated hycD) & This study \\
\hline BW25113 (pW/M735) & BW25113 (pBAD30 carries wild/mutated as/B) & This study \\
\hline BW25113 (pW/M875) & BW25113 (pBAD30 carries wild/mutated cdsA) & This study \\
\hline BW25113 (pW/M385) & BW25113 (pBAD30 carries wild/mutated acrB) & This study \\
\hline BW25113 (pW/M660) & BW25113 (pBAD30 carries wild/mutated nusG) & This study \\
\hline BW25113 (pW/M900) & BW25113 (pBAD30 carries wild/mutated rob) & This study \\
\hline BW25113 (pW/M950) & BW25113 (pBAD30 carries wild/mutated spoT) & This study \\
\hline BW25113 (pW/M425) & BW25113 (pBAD30 carries wild/mutated infB) & This study \\
\hline BW25113 (pW/M195) & BW25113 (pBAD30 carries wild/mutated rp/B) & This study \\
\hline D005 (W/M005) & BW25113 $\triangle p g s A:: \mathrm{cm}^{r}$ (pBAD30 carries wild/mutated pgsA) & This study \\
\hline D070 (pW/M070) & BW25113 $\triangle y e h Q:: \mathrm{cm}^{r}$ (pBAD30 carries wild/mutated yehQ) & This study \\
\hline D165 (pW/M165) & BW25113 $\triangle$ hycD:: $\mathrm{cm}^{r}$ (pBAD30 carries wild/mutated hycD) & This study \\
\hline D735 (pW/M735) & BW25113 $\triangle a s / B:: \mathrm{cm}^{r}$ (pBAD30 carries wild/mutated as/B) & This study \\
\hline D875 (pW/M875) & BW25113, $\Delta c d s A:: \mathrm{cm}^{r}$ (pBAD30 carries wild/mutated $c d s A$ ) & This study \\
\hline D385 (pW/M385) & BW25113, $\triangle a c r B:: \mathrm{cm}^{r}$ (pBAD30 carries wild/mutated $\left.a c r B\right)$ & This study \\
\hline D660 (pW/M660) & BW25113, $\triangle$ nusG.:: cm (pBAD30 carries wild/mutated nusG) & This study \\
\hline D900 (pW/M900) & BW25113, $\triangle$ rob:::cm (pBAD30 carries wild/mutated rob) & This study \\
\hline D950 (pW/M950) & BW25113, $\triangle$ spoT:: $\mathrm{cm}^{r}$ (pBAD30 carries wild/mutated spoT) & This study \\
\hline D425 (pW/M425) & BW25113, $\triangle$ infB:: $\mathrm{cm}^{r}$ (pBAD30 carries wild/mutated infB) & This study \\
\hline
\end{tabular}

of pyridine nucleotide transhydrogenase. The deletion mutant of each gene and mutant D123 with simultaneous deletion of the 17 genes (Additional file 1: Table S1) were constructed to test the butanol-tolerant function of these genes (Additional file 1: Table S5, Additional data). The large fragment deletion caused a slight growth inhibition but resulted in a slight improvement of butanol tolerance under $1-1.5 \%(\mathrm{v} / \mathrm{v})$ butanol stress (Additional file 1: Figure S2).

The deletion of each gene among the 17 genes did not affect growth. Gene TqsA (RS08380) deletion improved butanol tolerance performance of strains under high concentrations of butanol (above 1\%) stress, but not under relatively low-concentration $(0.5-0.75 \%)$ butanol stress (Table 3). The growth improvement of D380 was 34.6\%, $67.8 \%$ and $82.8 \%$ higher than that of BW25113 under $1 \%$, $1.25 \%$ and $1.5 \%(\mathrm{v} / \mathrm{v})$ butanol stress, respectively. The growth of D380 and BW25113 was both inhibited under $1.75 \%$ butanol stress, but the biomass of D380 was $136 \%$ higher than that of the control (Table 3). The overexpression of TqsA decreased butanol tolerance (Additional file 1: Figure S3). These data demonstrate that D380 has a significantly enhanced tolerance to increased butanol concentration of $1-1.5 \%$ (Table 3; Additional file 1: Figure S3). The deletion of $d g s A$ (RS08340) and $m d t$ J (RS08375) led to a slight decrease in butanol tolerance (Additional file 1: Figure S4B, C; Table S1). Nevertheless, the overexpression of $d g s A$ and $m d t J$ did not restore the tolerance level, which may be either due to plasmid and inducer interference or because neither gene has a significant tolerance function. The deletion of another 13 genes did not affect growth or butanol tolerance. Therefore, the deletion of TqsA plays an important role in tolerance under relatively high concentrations of butanol stress.

Multiple gene-deleted strains, D1 (with deletion of genes RS08320-RS08335), D2 (with deletion of genes RS08340-RS08375), D3 (with deletion of genes RS08380-RS08395), D12, D13, and D23, were constructed to investigate the effect of combined deletion on growth and tolerance. The growth and tolerance of the D2, D12, D23, and D13 strains were lower than that of the other strains, indicating that the deletion of RS08340-RS08375 leads to a decrease in growth (Additional file 1: Figure S5). The deleted fragment contained $d g s A$ and $m d t J$, further indicating that the simultaneous deletion of these two genes causes a slight inhibition 

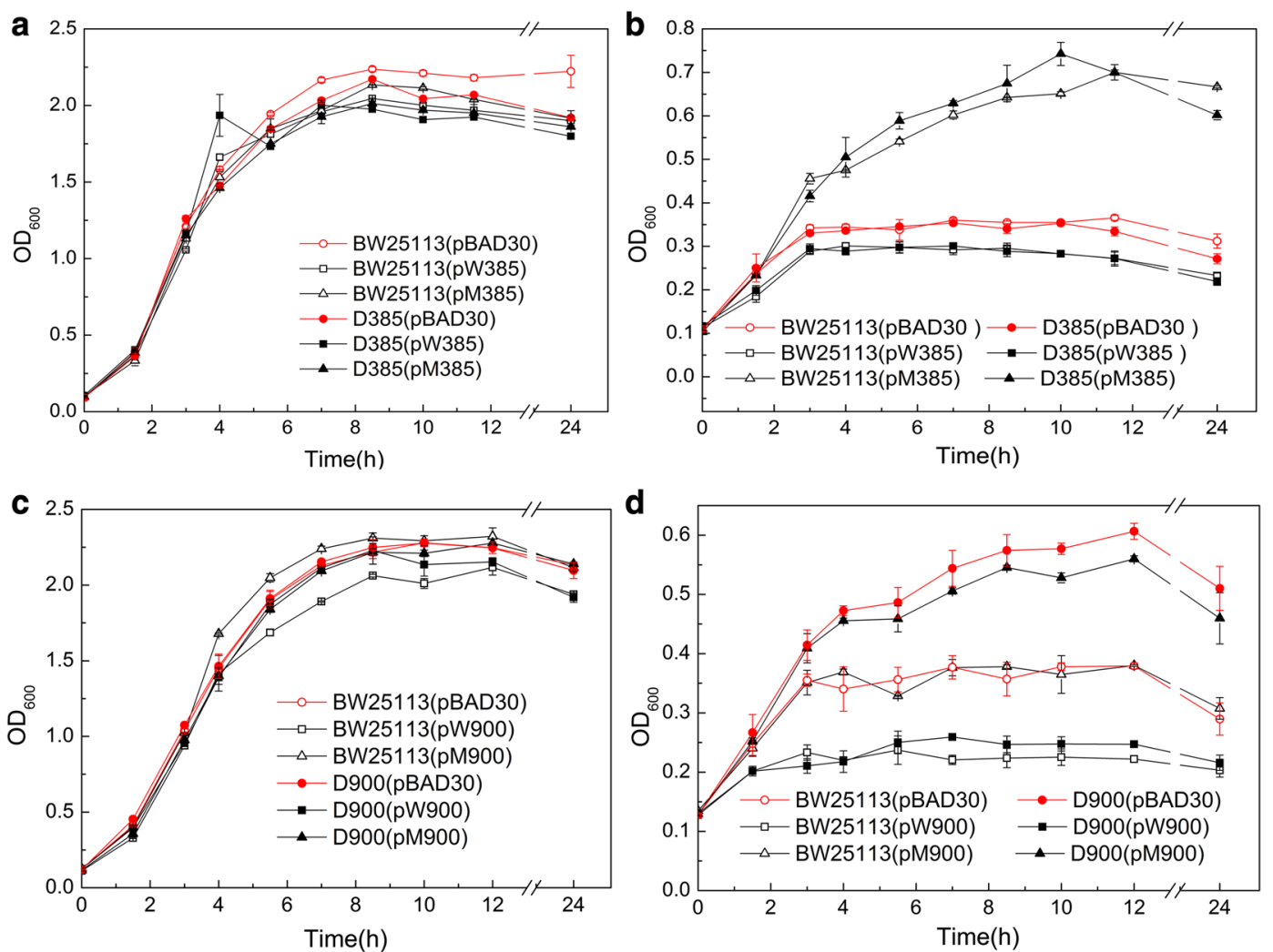

Fig. 4 Growth evaluation of $a c r B$ and rob overexpression strains. Serial $a c r B(\mathbf{a})$ and $r o b$ (b) gene overexpression strains were cultured in LB media with $(\mathbf{b}, \mathbf{d})$ and without butanol $(\mathbf{a}, \mathbf{c})$. The initial concentration of inoculation was controlled at $\mathrm{OD}_{600}=0.2$, and $0.02 \%$ ( $/ \mathrm{v}$ ) of $\mathrm{L}$-arabinose was added to the media to induce the expression of the target gene

Table 3 Growth improvement of the TqsA deletion mutant D380

\begin{tabular}{lcc}
\hline Butanol \% (V/V) & BW25113 & D380 \\
\hline 0.75 & $156.6 \pm 4.1$ & $122.1 \pm 1.5$ \\
1 & $52.8 \pm 3.1$ & $70.5 \pm 2.0$ \\
1.25 & $18.5 \pm 0.6$ & $31.0 \pm 0.7$ \\
1.5 & $6.0 \pm 0.6$ & $10.9 \pm 0.8$ \\
1.75 & $1.4 \pm 1.43$ & $3.3 \pm 1.0$ \\
\hline
\end{tabular}

D380 was cultured in LB containing $0.75-1.75 \%$ butanol, and its growth improvement was calculated according to formula (1) as described in "Methods" section

of growth and butanol resistance. Therefore, the deletion of TqsA is a key factor for improving the butanol tolerance characteristics of D123, BW1847, and BW1857 grown under $1-1.5 \%$ butanol stress.

\section{Butanol tolerance function of $r o b$ and $a c r B$ genes}

Two genome-wide site-specific mutants, DT385 (mutation of $\mathrm{C}_{1198} \mathrm{~T}$ in $a c r B$ gene) and DT900 ( $\mathrm{AT}_{686-7}$ deletion in $r o b$ gene), were constructed to study the effect of $a c r B$ and $r o b$ gene mutations on butanol tolerance and to eliminate the effect of plasmid and inducer arabinose on growth during tolerance evaluation. AcrB (formerly AcrE), a multidrug efflux RND transporter permease subunit, interacts with membrane fusion protein AcrA and outer-membrane protein TolC to form drug-efflux systems, which can efflux the toxic compounds, such as geraniol, limonene, and pinene, but not butanol $[6,9$, 22 . The growth curves of DT385 and the control strain grown in standard LB exhibited nearly identical trends, showing that the $\mathrm{C}_{1198}$ T mutation of $a c r B$ (Table 1) had no influence on cell growth (Fig. 5a). However, the maximum cell densities of D385 and DT385 were 1.9- and 1.6-fold higher than that of BW25113, respectively, when cultured with $0.75 \%(\mathrm{v} / \mathrm{v})$ butanol (Fig. $5 \mathrm{~b})$. The higher butanol concentration $(5.37-5.78 \mathrm{~g} / \mathrm{L})$ was found in the media of the two mutants compared to that in the control $(4.89 \mathrm{~g} / \mathrm{L})$. Moreover, the relative butanol content in one cell from D385 and DT385 was 0.60 and $0.54 \mathrm{~g} / \mathrm{L} / \mathrm{OD}_{600}$, respectively, which was lower than that of the control $\left(2.72 \mathrm{~g} / \mathrm{L} / \mathrm{OD}_{600}\right)$, indicating that the two strains had a higher butanol efflux ability than the control. These data demonstrate that both the deletion and point mutation of 
the $a c r B$ gene improved butanol tolerance as a result of the pumping of butanol out of the cells.

Interestingly, the functional complementation experiments showed that $a c r B$ deletion did not improve the butanol tolerance (Fig. 4). Arabinose was speculated to inhibit growth, such that D385 and DT385 were subsequently cultured in butanol media with and without L-arabinose for growth detection. Their maximum cell densities were lower (17.5-18.7\%) with L-arabinose than without it (Fig. 6), demonstrating growth inhibition by the addition of L-arabinose. Nevertheless, the deletion strain D385 still showed tolerance characteristics (Fig. 6). The presence of pBAD30 serial plasmids in D385 strain results in that the tolerance of D385 is not displayed. The growth of D385 harboring the plasmids was probably negatively affected by the combined effect of the arabinose, butanol, and metabolic burden of plasmids, which may cause an absence of tolerance.

The $r o b$ gene encodes OriC-binding transcriptional activator, and $\mathrm{AT}_{686-7}$ deletion of rob in genome did not affect growth (Fig. 5c) but caused a significant increase in growth under $0.75 \%(\mathrm{v} / \mathrm{v})$ butanol stress, indicating that deficiency of $\mathrm{AT}_{686-7}$ in rob can improve butanol

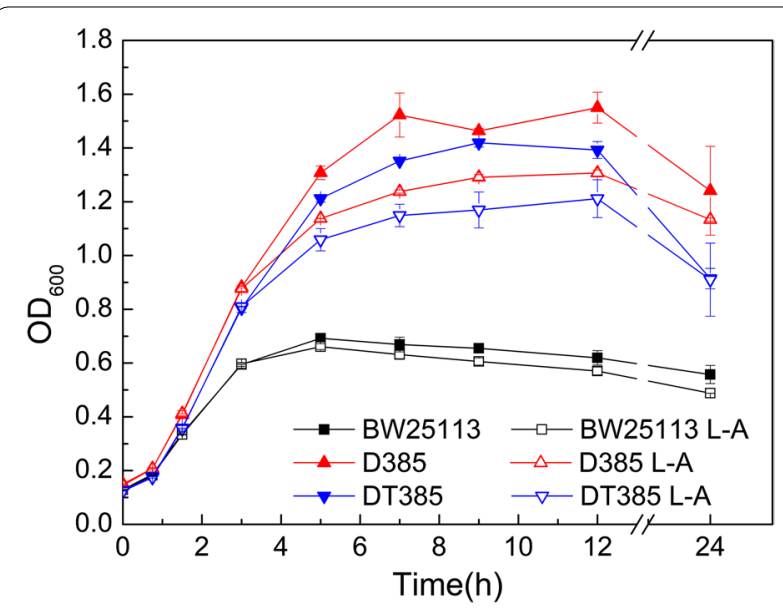

Fig. 6 Growth curve of mutant D385 and DT385 grown under butanol stress with and without L-arabinose. Mutants and the control BW25113 were cultured in LB medium with $0.75 \%$ butanol. Solid and hollow symbols indicate the cell densities of the strains grown in media with or without arabinose, respectively

tolerance(Fig. 5d). The rob-deleted strain D900 also showed higher tolerance, demonstrating that the truncated rob leads to its inactivation, causing an enhanced
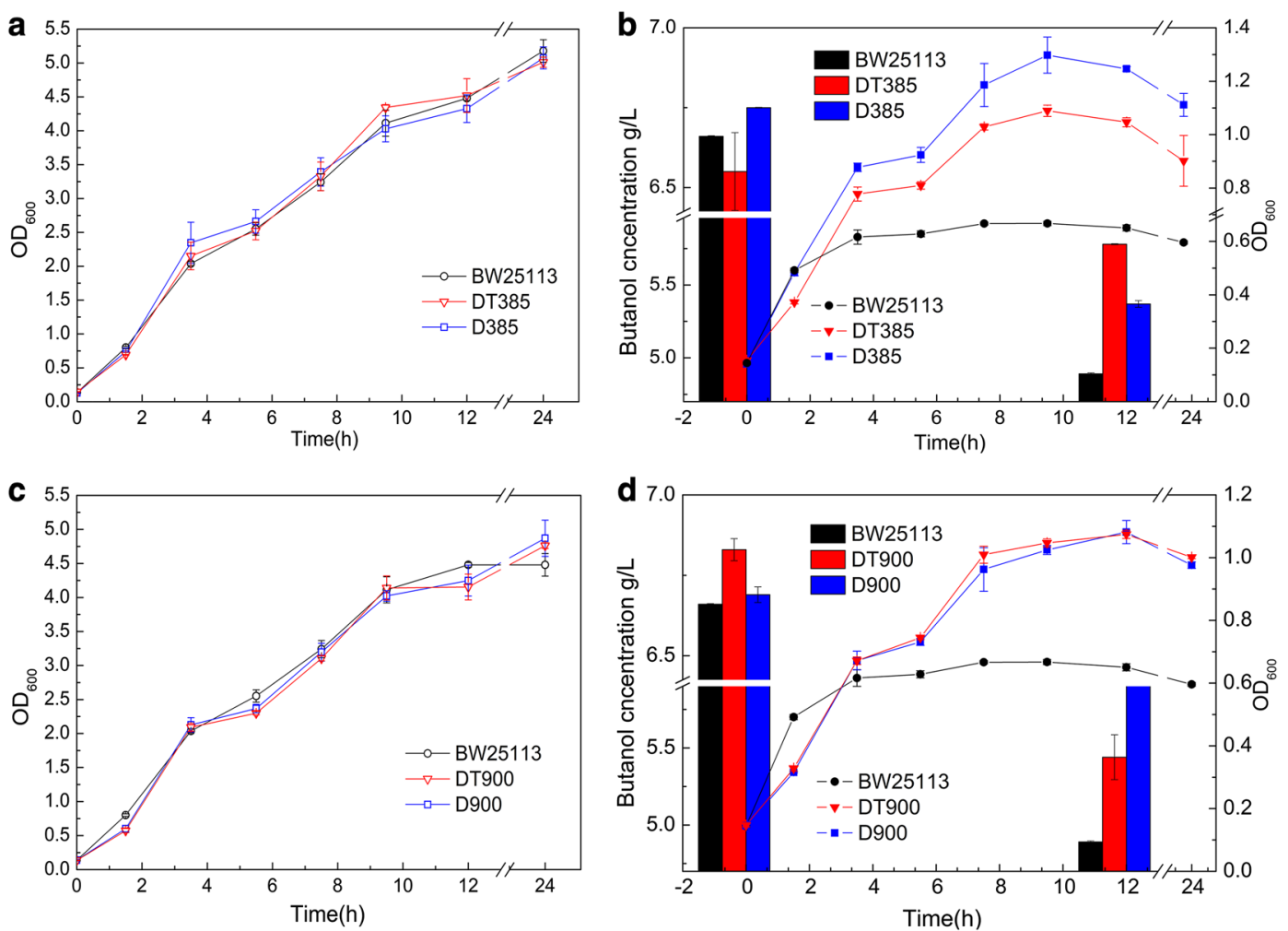

Fig. 5 Growth curve and butanol efflux of site-specific mutants. The mutant DT385 with mutated $a c r B_{C 1198 T}$ and DT900 with a truncated rob ${ }_{\text {AT686-7 }}$ gene were obtained by genome-wide site-specific methods. The two strains and their gene-deleted mutants D385 and D900 were cultured in LB with (b, d) or without $(\mathbf{a}, \mathbf{c}) \mathbf{0 . 7 5 \%}$ butanol. The left and right axes indicate the butanol concentration in media and the cell density $\left(\mathrm{OD}_{600}\right)$, respectively 
butanol tolerance. Moreover, the butanol efflux ability of the two mutants was also significantly improved (Fig. 5d). The inactivation of Rob could change the gene expression profile and corresponding physiological/biochemical processes under butanol stress. Some of the response genes regulated by Rob may function in the efflux of potentially toxic molecules to the outside of the cells.

\section{Discussion}

Bacterial genomes can be conveniently and rapidly modified using epPCR whole-genome shuffling with a highly efficient recombination system. The recombination efficiency of E. coli recombinase recA is very low [23]. Therefore, BW25113 (pKD46) containing a high-efficient recombinase system was chosen as the host. This resulted in two mutants, BW1847 and BW1857, which tolerated $2 \%$ butanol stress. Even though the growth of BW25113 decreased by $50 \%$ under $0.8 \%$ butanol stress [24], the two mutants in the study had a fourfold higher maximum cell density than BW25113 under 0.75\% butanol stress, indicating a great improvement in their butanol tolerance. Until now, most $E$. coli strains with single gene modifications could only tolerate $0.75-1.5 \%$ butanol stress [7, 13]. However, the two mutants obtained in this study showed better tolerance than most reported strains. A few mutants tolerating $2 \%$ butanol have been previously obtained via combined strategies or multi-gene mutations $[16,18]$, by which the function of multiple genes involved in various physiology events is changed to respond to stress. Even though multiple mutations can easily change physiological and biochemical functions, thereby yielding a better tolerance, they can lead to a decrease in tolerance function. Consequently, the identification of key resistant genes is necessary.

Many butanol-tolerant strains are also reported to show relevant tolerance to other short-chain alcohols, such as ethanol, isobutanol, 1-pentanol, 1,2,4-butanetriol, and $n$-propanol $[25,26]$. These short-chain alcohols possess similar molecular structures and exhibit toxicity. The fatty acid composition, structure, and fluidity of the cell membrane are similarly changed in response to stress by these short-chain alcohols. Therefore, the tolerance mechanism towards these alcohols is similar $[27,28]$.

BW1847 and BW1857 have 5 common SNPs, which also should be the mutations from BW184. However, functional complementation experiments carried out on each of these five genes did not confirm their butanol tolerance. As such, the tolerance of BW184 to butanol stress may result from the functional accumulation of all five mutated genes. The maximum cell density of BW1857 was lower than that of BW25113 and BW1847, and BW1857and BW1847 contained two different mutations, infB $B_{\text {deletion331-555 }}$ and $r p l B_{T 491 A}$. Nevertheless, the functional complementation experiments of the two mutated genes did not elucidate growth inhibition. Moreover, the deletion mutant and the point mutant strain of $r p l B$ could not be successfully obtained due to the deletion being lethal, neither is it easily edited by Cas9-sgRNA. However, the deletion of a 14-kb fragment in both strains leads to slight growth inhibition, suggesting that the combined actions of the two SNPs and the deleted genes cause growth inhibition of BW1857.

Interestingly, a 14-kb deletion was observed in both mutants, but large DNA fragment deletion was not reported to be present in other mutants obtained by epPCR-based genome shuffling [21, 29], which is because only a few mutants, obtained using this technology, are analyzed by genome resequencing [20]. Consequently, an attempt was made to demonstrate the origin of the $14-\mathrm{kb}$ deletion by experimentation and inference. If the deletion could be obtained by the lambda-Red recombination system of epPCR-based shuffling, then the deletion could have resulted from crossover recombination of a certain random epPCR product with coincident left and right homologous arm sequences of the target deletion fragment. The lambda-Red recombination system (pKD46), used in the shuffling, was used to knockout the target region, and twenty-nine transformants with 14-kb deletions were obtained (Additional file 1: Additional data, Figure S9, Table S11), indicating the possibility of deriving targeted deletions using this technology. Besides, final mutation rates of the two mutants were 1000-fold higher than the spontaneous mutation rates (Additional file 1: Additional data). Therefore, the 14-kb deletion was more likely due to homologous recombination of random epPCR products via lambda-Red recombinase used in the epPCR shuffling technology, than from spontaneous mutations during the recovery and screening phases after electroporation.

Three important tolerance genes were identified in this study: mutant $a c r B$, mutant $r o b$, and the deletion of Tqs $A$, all increased butanol tolerance. Mutated $\mathrm{AcrB}_{\mathrm{I} 466 \mathrm{~F}}$ is reported to pump butanol out of the cell, leading to an improvement in butanol tolerance [9]. $\mathrm{AcrB}_{\mathrm{L} 400 \mathrm{~F}}$ in this study is also found to exhibit butanol-efflux ability, and the mutated $1466 \mathrm{~F}$ and L400F are both located on the transmembrane domain, and would change the spatial structure. AcrB forms a trimer composed of loose (L), tight $(\mathrm{T})$, and open $(\mathrm{O})$ conformational states. Toxic compounds were bound to the $\mathrm{L}$ monomer and then transported to the $\mathrm{T}$ monomer, before finally being excreted out of cells by the $\mathrm{O}$ monomer [22] (Additional file 1: Figure $\mathrm{S} 6 \mathrm{~A}-\mathrm{C}$ ). The mutation in AcrB, thus, allowed for the binding and transportation of butanol, resulting in improved efflux function. Interestingly, $a c r B$ deficiency was reported to yield an improvement in butanol 
tolerance for the first time. This deletion resulted in an open funnel-shaped compound formed by AcrA and TolC in the periplasmic space (Additional file 1: Figure S6D), such that butanol was freely and directly transported out of cells by the uncompleted efflux pump system.

The transcription factor Rob responds to many stimuli, including antibiotics, organic solvents, and oxidative stressors, and its function in resistance to the stress is shown by overexpression of Rob through a plasmid [32-34]; while, the rob-deleted strains exhibit a decreased tolerance to the stresses [33, 34]. Nevertheless, the inactivation of Rob in this study enhanced the butanol tolerance (Figs. 4, 5). The Rob-inactive strain would have a different expression profile than the wild-type under butanol stress. The response genes, and thus the physiological roles regulated by Rob would be interesting and complex, and should be investigated to provide insights into the mechanism of butanol tolerance in future studies.

The deletion of TqsA, encoding an AI-2 transporter, was found to improve the butanol tolerance. Transmembrane protein TqsA transports quorum-sensing molecule AI- 2 out of the cells, and its deletion increases the concentration of intracellular AI-2, which enhances the motility of cells, allowing cells to escape from toxic compounds [35, 36], and improves the biofilm thickness by up-regulating the expression of lipopolysaccharide (LPS)synthesis-related genes $[37,38]$. Therefore, the deletion of TqSA may lead to the improvement of intracellular AI-2, which subsequently increases cell motility and biofilm thickness, resulting in enhanced butanol tolerance.

Both the mutation and the deletion strain of $a c r B$ and rob improved growth by about 1.7- to 2.0-fold, compared to the control BW25113 under $0.75 \%$ butanol stress (Additional file 1: Table S10). The deletion of TqsA led to an improved tolerance (1.7-fold) in high concentration butanol media (1-1.25\%). These three genes result in features for butanol tolerance, which could provide target genes for the engineering of a butanol-tolerant strain. The co-expression of these three genes is speculated to be able to result in an accumulated improvement of tolerance, which should be interesting and would be investigated further in future studies.

Among the 17 deleted and 11 mutated genes from the two mutants, only three genes were identified to exhibit significant butanol tolerance in this study. Correspondingly, among 16 mutated genes in mutant E72, only three mutations were beneficial [39]. These results demonstrate that only a few of multiple mutations may be valuable for functional improvement. Some mutations may produce an unobvious objective function or cause decreased target function. Therefore, improved characteristics in a mutant with random mutations may result from the combined actions of several key mutated genes. Consequently, the identification of key functional genes is important for revealing a corresponding mechanism and providing genetic resources for the construction of optimal chassis strains using rational metabolic engineering strategies.

\section{Conclusions}

Two stable and high-concentration butanol-tolerant $E$. coli mutants were obtained by epPCR-based genome shuffling, a rapid and effective method. The two mutants were found to also tolerate short alcohols. Their mutation genes were revealed through genome resequencing. A comparative functional genomic study identified the key genes involved in butanol tolerance in both mutants, including $r o b$, encoding transcript regulator factor Rob, $a c r B$, encoding efflux pump transporter, and tqs $A$, encoding a quorum-sensing molecule transporter. The mutation or deletion of these three genes resulted in an improvement in butanol tolerance. Interestingly, the present data found for the first time that the deletion of $a c r B$ and $r o b$ yielded a significantly increased butanol-efflux ability, and the deletion of tqsA caused slight growth inhibition and highconcentration butanol-tolerance characteristics. These surprising and novel gene functions could provide a new point of view for the investigation of tolerance mechanism. This study, thus, provides valuable information for the construction of butanol-resistant strains and insights into the mechanism of butanol tolerance.

\section{Methods}

\section{Strains and culture conditions}

E. coli BW25113 (pKD46) was used as a starting strain. Strain BW1847 was deposited in the China Center for Type Culture Collection (CCTCC; Accession NO. M2015365). All E. coli strains were cultured in LuriaBertani (LB) medium (5 g/L yeast extract, $10 \mathrm{~g} / \mathrm{L}$ Casein tryptone, and $10 \mathrm{~g} / \mathrm{L} \mathrm{NaCl}$ ) at $30^{\circ} \mathrm{C}$ or $37^{\circ} \mathrm{C}$ with 180 $200 \mathrm{rpm}$ shaking for growth.

\section{Error-prone PCR-based genome shuffling of E. coli}

Genomic DNA of E. coli BW25113 was extracted from $2 \mathrm{~mL}$ of overnight cell culture and then used for the epPCR templates. EpPCR was conducted according to the protocols developed by Ye et al. [21] with some modifications [20] (Fig. 1a). The amplified PCR products were then concentrated 5- to 10-fold by ethanol-precipitated for electro-transformation (Additional file 1: Additional data).

Escherichia coli BW25113 (pKD46) were cultured in LB media with $100 \mu \mathrm{g} / \mathrm{mL}$ ampicillin at $30{ }^{\circ} \mathrm{C}$ until optical density at $600 \mathrm{~nm}\left(\mathrm{OD}_{600}\right)$ reached $0.15-0.2$, and then 
L-arabinose was added to the media at a final concentration of $20 \mathrm{mM}$ to induce expression of lambda-Red recombinase. When the cultures reached an $\mathrm{OD}_{600}$ of $0.45-0.5$, electro-competent cells were prepared. Competent cells $(40 \mu \mathrm{L})$ were mixed with $1-5 \mu \mathrm{L}$ of ethanol-precipitated PCR products, and the mixture was incubated in ice bath for $5 \mathrm{~min}$ and then transferred to a pre-chilled 1-mm-gap electroporation cuvette (Eppendorf, Germany). The cells were electroporated with a pulse of $1800 \mathrm{v}$ at $5 \mathrm{~ms}$ using Electroporator 2510 (Eppendorf, Germany), and the suspensions were immediately mixed with $1 \mathrm{~mL}$ of LB broth and transferred to a microcentrifuge tube for culture at $37{ }^{\circ} \mathrm{C}$ with $100-110 \mathrm{rpm}$ shaking for $1 \mathrm{~h}$. About $200 \mu \mathrm{L}$ of culture was then spread on LB agar plates containing an initial $1.2 \%, 1.4 \%, 1.6 \%$ and $1.8 \%$ (v/v) butanol, respectively. After $16-24 \mathrm{~h}$ of $37^{\circ} \mathrm{C}$ incubation, the transformants were picked up from these plates and inoculated into 4-mL LB containing $0.7-0.9 \%$ butanol for growth evaluation. The best butanol-tolerant mutant was used for subsequent round of shuffling. The pKD46 plasmid was extracted and then transformed to the target strain to provide recombinase system for next round of shuffling (Fig. 1a).

\section{Butanol tolerance assay}

Growth differences among transformants from each round of genome shuffling were preliminarily evaluated in $20-\mathrm{mL}$ test tubes and sealed with a screw cap. The single clones were inoculated into 3-mL LB with $0.5 \%(\mathrm{v} / \mathrm{v})$ butanol for adaptive growth. These strains and BW25113 were then inoculated into LB for preculture. The overnight seed cultures were transferred to tubes with 4-mL LB containing 0.7 and $0.9 \%$ butanol for screening butanol-tolerant mutants in the 1st and 2 nd rounds of shuffling, respectively. The cultures were taken each $4 \mathrm{~h}$ for determination of the $\mathrm{OD}_{600}$ values. The butanol-tolerant strains were picked for further shake-flask evaluation. The cultures of these mutants obtained by each round of shuffling and control strain BW25113 were pre-cultured as aforementioned, and then inoculated to 250-mL screw-cap conical flasks containing $50-\mathrm{mL} \mathrm{LB}$ with $0.95 \%$ butanol with an initial $\mathrm{OD}_{600}$ of $0.1-0.2$ for growth evaluation. Butanol tolerance evaluation of BW1847 and BW1857 was performed in the presence of high concentration of butanol (1.6-2.0\%). Growth curves of the two strains and control BW25113 were drawn, and their growth improvement was calculated according to the following formula. And the growth improvement of the strain D380 was also evaluated and calculated using this formula.

$$
\text { growth improvement }(\%)=\frac{\mathrm{OD}_{600, \max }-\mathrm{OD}_{600, \text { initial }}}{\mathrm{OD}_{600, \text { initial }}} \times 100
$$

\section{Determination of short-chain alcohol tolerance of BW1847 and BW1857}

Seed cultures of BW1847, BW1857 and BW25113 were prepared as aforementioned and then inoculated into 4-mL LB with butanol (0-1.5\%), isobutanol (0-1.5\%), and ethanol (0-7\%), 1-pentanol (0-0.5\%), acetic acid $(0-0.3 \%)$, respectively. Strains were cultured at $37{ }^{\circ} \mathrm{C}$ with $200-\mathrm{rpm}$ shaking, and initial $\mathrm{OD}_{600}$ was controlled at 0.1 . The $\mathrm{OD}_{600}$ values at $12 \mathrm{~h}$ were determined, and the relative $\mathrm{OD}_{600}$ ratios of transformants to control BW25113 cultured under same conditions were calculated to evaluate the butanol tolerance.

\section{Growth and butanol concentration detection}

All growth detection experiments in butanol stress were performed using screw-cap test tubes or conical flasks as aforementioned. Cell density was determined by $\mathrm{OD}_{600}$ with a Cary 50 spectrophotometer (Varian Inc.). Butanol concentration in media during culture was detected by high-performance liquid chromatography (HPLC) using Organic Acid Analysis Column (Aminex HPX-87H Ion Exclusion Column, $300 \mathrm{~mm} \times 7.8 \mathrm{~mm})$ at $45{ }^{\circ} \mathrm{C}$ and sulphuric acid $(4 \mathrm{mM})$ as mobile phrase at $0.8 \mathrm{~mL} / \mathrm{min}$. The butanol concentration at $12 \mathrm{~h}$ was subtracted from the initial butanol concentration in the media, and then divided by the $\mathrm{OD}_{600}$ value of strain grown at $12 \mathrm{~h}$ to obtain the relative butanol content in one cell from each strain, which is used to measure the butanol-efflux ability of cells. All experiments for growth evaluation were performed in triplicates, and statistical differences were analyzed using ANOVA, Single star indicated $p \leq 0.05$. The heights of the bars and the error bars in figures indicated the means \pm standard deviations.

\section{Evaluation of butanol-tolerance stability of BW1847 and BW1857}

Strain BW25113, BW1847 and BW1857 were cultured in $\mathrm{LB}$ medium until $\mathrm{OD}_{600}$ value reached 4 . These strains were then serially transferred ten times (about 50-60 generation) into fresh LB medium with an initial inoculation concentration of $1 \%(\mathrm{v} / \mathrm{v})$. The serial cultures and the cultures stored in glycerol were all inoculated into 3-mL LB media, and pre-cultured for $12-15 \mathrm{~h}$ with $200-\mathrm{rpm}$ shaking. All the pre-cultures were then transferred into 10-mL LB media for the second pre-culture. After $12 \mathrm{~h}$ of incubation, the second pre-cultures were inoculated into 250-mL screw-cap conical flask with 50-mL LB containing $0,0.75,1.0,1.25$ and $1.5 \%(\mathrm{v} / \mathrm{v})$ butanol for growth evaluation, respectively. The initial $\mathrm{OD}_{600}$ was controlled at 0.2 , and the $\mathrm{OD}_{600}$ value was determined every $4 \mathrm{~h}$ for comparison of growth curves. 


\section{Genome resequencing of mutants and identification of Single Nucleotide Polymorphism (SNP)}

Genomic DNA of BW1847 and BW1857 was submitted to Meiji Company (Shanghai) and Novogene (Beijing) for genome resequencing, respectively. Genome sequence of BW25113 (NZ-CP009273.1) was used as a reference sequence for mutation analysis. The sequencing data were deposited in Genebank (SRA accession No. PRJNA397315 and No. PRJNA399799 for BW1847 and BW1857, respectively). The mutated genes were amplified by PCR with $2 \times$ Pfu Mastermix (Kangwei Biotech Co. Beijing, China) for sequencing confirmation (Additional file 1: Additional data).

To confirm a deletion of a large gene fragment in genome of BW1857, PCR identification was performed using the genomic DNA of BW1857 as template and primer sets QS-F and QS-R (Additional file 1: Table S1, Additional data), which was located in upstream and downstream of the deleted gene fragment, respectively. The PCR products were then sequencing verified (Sangong Biotech, Shanghai, China).

\section{Construction of deletion and overexpression strains}

Knockout of each mutated gene was performed according to Datsenko et al's reports [24] with a minor modification (Additional file 1: Additional data) for functional identification of the mutated genes in BW1847 and BW1857. Overexpression vectors were constructed by ligating the target wild-type gene and its mutated gene into multiple clone sites of pBAD30 vector (as described in Additional file 1: Additional data, Tables S1-S5, Figure S7), yielding the pBAD30-Wgene and the pBAD30Mgene plasmid, respectively (Table 2). The plasmids were then transferred into strain BW25113 and a targetgene-deleted strain Dgene (Additional file 1: Table S5), and the serial strains were obtained (Table 2), including BW25113 (pBAD30-Wgene), BW25113 (pBAD30Mgene), BW25113 (pBAD30), Dgene (pBAD30-Wgene), Dgene (pBAD30-Mgene) and Dgene (pBAD30).

\section{Functional identification of deleted genes in BW1847 and BW1857}

Knockout of each gene in the large deleted fragment of BW1857 (Table 1) was performed according to the above description (Additional file 1: Additional data). These mutants (Additional file 1: Table S5) and control BW25113 were inoculated into 3-mL LB liquid media for $12 \mathrm{~h}$ pre-culture. The subcultures were then transferred into $25 \mathrm{~mL}$ of tubes containing 4-ml LB liquid medium with $0,0.5 \%$, and $0.75 \%(\mathrm{v} / \mathrm{v})$ butanol, respectively. The initial $\mathrm{OD}_{600}$ was controlled at 0.1 , and the $\mathrm{OD}_{600}$ were measured at 0 and $12 \mathrm{~h}$ to preliminarily evaluate their growth difference. The strains that showed higher cell densities than BW25113 were selected to measure growth curves. These transformants and BW25113 were subcultured as described above, and then transferred into 250-mL conical flasks which contained 50-mL LB liquid medium with $0,0.5 \%$ and $0.75 \%(\mathrm{v} / \mathrm{v})$ butanol, respectively. The initial $\mathrm{OD}_{600}$ was controlled at 0.1 , and the $\mathrm{OD}_{600}$ value was measured every 1.5 or $2 \mathrm{~h}$ to observe the growth difference between transformants and control.

\section{Site-specific genomic mutation and deletion in E. coli}

Strains with the large fragment deletion (D123) and partially deleted genes (D1, D2, D3, D12, D13 and D23) were constructed using CRISPR/Cas9 [40] system according to the order of deleted genes on genome (Additional file 1: Tables S5, S7 and S8, Additional data) to detect the combined impact of several deleted genes on 14-kb deletion fragment on growth. Genome-wide site-specific mutant DT385 (mutation of $\mathrm{C}_{1198} \mathrm{~T}$ in $a c r B$ gene) and strain DT900 ( $\mathrm{AT}_{686-7}$ deletion in rob gene) were constructed using scarless gene modification strategy according to the previous reports $[41,42]$ with some modification (Additional file 1: Additional data, Table S9, Figure S8).

\section{Additional file}

Additional file 1.

\section{Authors' contributions}

YM designed the experiments, analyzed the data and wrote the manuscript. $\mathrm{XH}, \mathrm{TX}, \mathrm{JZ}, \mathrm{JH}$ carried out experiments and drafted the manuscript. XH, TX and $J Z$ carried out all experiments. LH, JQ and HS designed the experiments and drafted the manuscript. YM, JQ, HS and MZ supervised the study and revised the manuscript. All authors read and approved the final manuscript.

\section{Author details \\ ${ }^{1}$ Biomass Conversion Laboratory, R\&D Center for Petrochemical Technology, Tianjin University, Tianjin 300072, People's Republic of China. ${ }^{2}$ Department of Biochemical Engineering, School of Chemical Engineering and Technol- ogy, Tianjin University, Tianjin 300072, People's Republic of China. ${ }^{3}$ Frontier Technology Research Institute, Tianjin University, Tianjin 30072, People's Republic of China. ${ }^{4}$ Collaborative Innovation Centre of Chemical Science and Engineering (Tianjin), Tianjin 300072, China. ${ }^{5}$ Key Laboratory of Systems Bioengineering (Ministry of Education), SynBio Research Platform, Tianjin University, Tianjin 300072, China. ${ }^{6}$ Tianjin Key Laboratory of Pulp and Paper, Tianjin University of Science and Technology, Tianjin 300457, China.}

\section{Acknowledgements}

The authors appreciate Prof. Sheng Yang for kindly providing CRISPR-Cas9 system, and thank Prof. Tao Chen and Prof. Zhiwen Wang for kindly providing site-specific mutagenesis tool. The author would like to thank Zheng Hu and Jingxiao Ji for data analysis of genome resequencing. The author would also like to thank the members of Novogene for their valuable informations on the sequence submission to NCBI.

\section{Competing interests}

The authors declare that they have no competing interests. 


\section{Availability of data and materials}

Not applicable.

\section{Consent for publication}

Authors agreed to publish this article.

\section{Ethics approval and consent to participate}

Not applicable.

\section{Funding}

This research was supported by the National Natural Science Foundation of China (NSFC 30900033), and the Natural Science Foundation of Tianjin (18JCYBJC24200).

\section{Publisher's Note}

Springer Nature remains neutral with regard to jurisdictional claims in published maps and institutional affiliations.

Received: 22 August 2018 Accepted: 12 March 2019

Published online: 01 April 2019

\section{References}

1. Jiang Y, Liu J, Jiang W, Yang Y, Yang S. Current status and prospects of industrial bio-production of $n$-butanol in China. Biotechnol Adv. 2015;33(7):1493-501.

2. Dong H, Zhao C, Zhang T, Zhu H, Lin Z, Tao W, Zhang Y, Li Y. A systematically chromosomally engineered Escherichia coli efficiently produces butanol. Metab Eng. 2017;44:284-92.

3. Shen CR, Lan El, Dekishima Y, Baez A, Cho KM, Liao JC. Driving forces enable high-titer anaerobic 1-butanol synthesis in Escherichia coli. Appl Environ Microbiol. 2011;77(9):2905-15

4. Dong H, Zhao C, Zhang T, Lin Z, Li Y, Zhang Y. Engineering Escherichia coli cell factories for $n$-butanol production. Adv Biochem Eng Biotechnol. 2016;155:141-63.

5. Nanda S, Golemi-Kotra D, McDermott JC, Dalai AK, Gökalp I, Kozinski JA. Fermentative production of butanol: perspectives on synthetic biology. Nat Biotechnol. 2017:37(Pt B):210-21.

6. Siu Y, Fenno J, Lindle JM, Dunlop MJ. Design and selection of a synthetic feedback loop for optimizing biofuel tolerance. ACS Synth Biol. 2018:7(1):16-23.

7. Boyarskiy S, Davis López S, Kong N, Tullman-Ercek D. Transcriptional feedback regulation of efflux protein expression for increased tolerance to and production of $n$-butanol. Metab Eng. 2016;33:130-7.

8. Dunlop MJ, Dossani ZY, Szmidt HL, Chu HC, Lee TS, Keasling JD, Hadi MZ, Mukhopadhyay A. Engineering microbial biofuel tolerance and export using efflux pumps. Mol Syst Biol. 2011;7:487.

9. Fisher MA, Boyarskiy S, Yamada MR, Kong N, Bauer S, Tullman-Ercek D. Enhancing tolerance to short-chain alcohols by engineering the Escherichia coli AcrB efflux pump to secrete the non-native substrate $n$-butanol. ACS Synth Biol. 2014;3(1):30-40.

10. Reyes LH, Abdelaal AS, Kao KC. Genetic determinants for n-butanol tolerance in evolved Escherichia coli mutants: cross adaptation and antagonistic pleiotropy between $n$-butanol and other stressors. Appl Environ Microbiol. 2013;79(17):5313-20.

11. Reyes LH, Almario MP, Kao KC. Genomic library screens for genes involved in n-butanol tolerance in Escherichia coli. PLoS ONE. 2011;6(3):e17678.

12. Chin WC, Lin KH, Chang JJ, Huang CC. Improvement of $n$-butanol tolerance in Escherichia coli by membrane-targeted tilapia metallothionein. Biotechnol Biofuels. 2013;6(1):130.

13. Abdelaal AS, Ageez AM, Abd El-Hadi AE, Abdallah NA. Genetic improvement of $n$-butanol tolerance in Escherichia coli by heterologous overexpression of groESL operon from Clostridium acetobutylicum. 3 Biotech. 2015;5(4):401-10.

14. Lee JY, Yang KS, Jang SA, Sung BH, Kim SC. Engineering butanol-tolerance in Escherichia coli with artificial transcription factor libraries. Biotechnol Bioeng. 2011:108(4):742-9.
15. Reyes LH, Almario MP, Winkler J, Orozco MM, Kao KC. Visualizing evolution in real time to determine the molecular mechanisms of $n$-butanol tolerance in Escherichia coli. Metab Eng. 2012;14(5):579-90.

16. Si HM, Zhang F, Wu AN, Han RZ, Xu GC, Ni Y. DNA microarray of global transcription factor mutant reveals membrane-related proteins involved in $n$-butanol tolerance in Escherichia coli. Biotechnol Biofuels. 2016;9:114.

17. Zhu L, Cai Z, Zhang Y, LiY. Engineering stress tolerance of Escherichia coli by stress-induced mutagenesis (SIM)-based adaptive evolution. Biotechnol J. 2014:9(1):120-7.

18. Bui LM, Lee JY, Geraldi A, Rahman A, Lee JH, Kim SC. Improved n-butanol tolerance in Escherichia coli by controlling membrane related functions. J Biotechnol. 2015;204:33-44.

19. Zhao XM, Chen T, Wang ZW. Metabolic engineering. Beijing: Higher Education Press; 2015

20. Huang S, Xue T, Wang Z, Ma Y, He X, Hong J, Zou S, Song H, Zhang M. Furfural-tolerant Zymomonas mobilis derived from error-prone PCR-based whole genome shuffling and their tolerant mechanism. Appl Microbiol Biotechnol. 2018:102(7):3337-47.

21. Ye L, Zhao H, Li Z, Wu JC. Improved acid tolerance of Lactobacillus pentosus by error-prone whole genome amplification. Bioresour Technol. 2013;135:459-63.

22. Seeger MA, Schiefner A, Eicher T, Verrey F, Diederichs K, Pos KM. Structural asymmetry of AcrB trimer suggests a peristaltic pump mechanism. Science. 2006;313(5791):1295-8.

23. Datsenko KA, Wanner BL. One-step inactivation of chromosomal genes in Escherichia coli K-12 using PCR products. Proc Natl Acad Sci. 2000:97(12):6640-5.

24. Rutherford RJ, Dahl RH, Price RE, Szmidt HL, Benke PI, Mukhopadhyay A, Keasling JD. Functional genomic study of exogenous $n$-butanol stress in Escherichia coli. Appl Environ Microbiol. 2010;76(6):1935-45.

25. Royce LA, Yoon JM, Chen Y, Rickenbach E, Shanks JV, Jarboe LR. Evolution for exogenous octanoic acid tolerance improves carboxylic acid production and membrane integrity. Metab Eng. 2015;29:180-8.

26. Zingaro KA, Papoutsakis ET. GroESL overexpression imparts Escherichia coli tolerance to $i$-, $n$-, and 2-butanol, 1,2,4-butanetriol and ethanol with complex and unpredictable patterns. Metab Eng. 2013;15:196-205.

27. Li J, Zhao JB, Zhao M, Yang YL, Jiang WH, Yang S. Screening and characterization of butanol-tolerant microorganisms. Lett Appl Microbiol. 2010;50(4):373-9

28. Liu S, Qureshi N. How microbes tolerate ethanol and butanol. Nat Biotechnol. 2009;26(3-4):117-21.

29. Luhe AL, Tan L, Wu J, Zhao H. Increase of ethanol tolerance of Saccharomyces cerevisiae by error-prone whole genome amplification. Biotechnol Lett. 2011;33(5):1007-11.

30. Duval V, Lister IM. MarA, SoxS and Rob of Escherichia coli-global regulators of multidrug resistance, virulence and stress response. Int J Biotechnol Wellness Ind. 2013:2(3):101-24.

31. Nakajima H, Kobayashi K, Kobayashi M, Asako H, Aono R. Overexpression of the robA gene increases organic solvent tolerance and multiple antibiotic and heavy metal ion resistance in Escherichia coli. Appl Environ Microbiol. 1995;61(6):2302-7.

32. Sharma P, Haycocks JRJ, Middlemiss AD, Kettles RA, Sellars LE, Ricci V, Piddock LJV, Grainger DC. The multiple antibiotic resistance operon of enteric bacteria controls DNA repair and outer membrane integrity. Nat Commun. 2017:8(1):1444

33. Bennik MH, Pomposiello PJ, Thorne DF, Demple B. Defining a rob regulon in Escherichia coli by using transposon mutagenesis. J Bacteriol. 2000:182(13):3794-801.

34. White DG, Goldman JD, Demple B, Levy SB. Role of the acrAB locus in organic solvent tolerance mediated by expression of marA, soxS, or robA in Escherichia coli. J Bacteriol. 1997;179(19):6122-6.

35. Herzberg M, Kaye IK, Peti W, Wood TK. YdgG (TasA) controls biofilm formation in Escherichia coli K-12 through autoinducer 2 transport. $J$ Bacteriol. 2006;188(2):587-98.

36. Kim YJ, Im SY, Lee JO, Kim OB. Potential swimming motility variation by AcrR in Escherichia coli. J Microbiol Biotechnol. 2016;26(10):1824-8.

37. De Araujo C, Balestrino D, Roth L, Charbonnel N, Forestier C. Quorum sensing affects biofilm formation through lipopolysaccharide synthesis in Klebsiella pneumoniae. Res Microniol. 2010;161(7):595-603. 
38. Shao C, Shang W, Yang Z, Sun Z, Li Y, Guo J, Wang X, Zou D, Wang S, Lei H, et al. LuxS-dependent Al-2 regulates versatile functions in Enterococcus faecalis V583. J Proteome Res. 2012;11(9):4465-75.

39. Zhang B, Li N, Wang ZW, Tang YJ, Chen T, Zhao XM. Inverse metabolic engineering of Bacillus subtilis for xylose utilization based on adaptive evolution and whole-genome sequencing. Appl Microbiol Biotechnol. 2015:99:885-96.

40. Jiang Y, Chen B, Duan C, Sun B, Yang J, Yang S. Multigene editing in the Escherichia coli genome via the CRISPR-Cas9 system. Appl Environ Microbiol. 2015;81(7):2506-14.
41. Lin Z, Xu Z, Li Y, Wang Z, Chen T, Zhao X. Metabolic engineering of Escherichia coli for the production of riboflavin. Microb Cell Fact. 2014;13:104.

42. Zhang Y, Lin Z, Liu Q, Li Y, Wang Z, Ma H, Chen T, Zhao X. Engineering of serine-deamination pathway, Entner-Doudoroff pathway and pyruvate dehydrogenase complex to improve poly (3-hydroxybutyrate) production in Escherichia coli. Microb Cell Fact. 2014;13:172.
Ready to submit your research? Choose BMC and benefit from:

- fast, convenient online submission

- thorough peer review by experienced researchers in your field

- rapid publication on acceptance

- support for research data, including large and complex data types

- gold Open Access which fosters wider collaboration and increased citations

- maximum visibility for your research: over $100 \mathrm{M}$ website views per year

At BMC, research is always in progress.

Learn more biomedcentral.com/submissions 